\title{
El streaming como medio de supervivencia para la Radio. Caso "emisora La Voz de Pereira"
}

\author{
Juan Sebastián López Carmona'
}

RESUMEN Los medios de comunicación cada día están en constante evolución, para lo cual buscan innovar sus transmisiones. A través del tiempo, el público va cambiando: las personas, las nuevas generaciones, las transformaciones en el tiempo y la época, hacen que se pierda interés por lo que algún día fue "el gran impacto y revolución de la sociedad". Por lo tanto, puede decirse que las personas mayores son las que aún guardan el gusto por encender la radio, escuchar las noticias y recordar tiempos pasados. En contraste, los nacidos en el Siglo XXI utilizan y se emocionan con lo digital, donde la gran mayoría de herramientas que ofrece el mercado, se encuentran al alcance de los dispositivos móviles. Es por ello que el streaming llega como una forma de supervivencia para la radio, volviendo de esta manera a revolucionar dicho medio, proveyendo a la gente una nueva opción de escuchar su música y programas favoritos desde la comodidad de sus habitaciones, o incluso sintonizarlas en el auto, en moto, o en cualquier medio de transporte, dando una pequeña luz a un medio de comunicación tradicional, que aparentemente está muriendo con el vertiginoso advenimiento tecnológico de nuestros días.

PALABRAS

Streaming;

CLAVE

Supervivencia;

Medio Digital;

Radio. 


\section{Streaming as a means of survival for Radio. Caso La Voz de Pereira Pereira}

ABSTRACT The media are constantly evolving, seeking to innovate their transmissions. Over time, the public is changing: people, the new generations, the transtormations of time and time, make it lose interest in what one day was the "great impact and revolution of society". It can therefore be said that older people still have a taste for turning on the radio, listening to the news and remembering times gone by. In contrast, those born in the 21 st century use and are excited about digital, where the vast majority of tools offered by the market are within the reach of mobile devices. That is why streaming comes as a form of survival for radio, thus returning to revolutionizing that medium, providing people with a new option to listen to their favorite music and programs from the comfort of their rooms, or even tune them into the car, on a motorcycle, or in any mode of transport, giving a small light to a traditional means of communication, which is apparently dying with the dizzying technological advent of our day.

Streaming;

KEYWORDS Survival;

Digital Media;

Radio. 


\section{INTRODUCCIÓN}

A través de esta investigación, se pretende conocer la radio digital en la ciudad de Pereira a partir de la emisora 'La Voz de Pereira', con el fin de conocer el proceso desde los inicios de la era digital hasta hoy. Esta ha sido una de las emisoras con mayor importancia en la ciudad, ya que después de su desaparición durante las últimas décadas del siglo XX, renace cuando el creador del Digital Book en Colombia, decide crear su propia emisora streaming con el nombre de la que fue una de las más relevantes del Eje Cafetero y del País. Pereira, Colombia, ubicada en la región centro occidental, es una de las ciudades alrededor del mundo en el que muchas emisoras radiales han pasado del medio análogo al medio digital durante la última década. Este medio es lo que hoy conocemos como la radio streaming, la cual se ha adaptado a las necesidades y preferencias de las audiencias más jóvenes.

El streaming es la distribución de contenido multimedia a través de internet, que en los últimos años ha sido una herramienta muy valiosa para los medios de comunicación, entre los cuales está la radio, la cual, por internet, también conocida como radio online, ha sido de gran ayuda a las emisoras radiales alrededor del mundo como una forma de sobrevivir a la era digital, pues el público ha ido evolucionando y dejando de hacer uso de los medios análogos para migrar a las nuevas tecnologías. En el momento que conozcamos y entendamos cómo ha funcionado la radio en nuestro país y principalmente en Pereira desde su llegada y cómo esta se encuentra migrando al medio digital, los públicos podrán sentirse atraídos hacia este medio de comunicación.

"Colombia, desde sus inicios han adoptado los mejores equipos de radiodifusión, gracias a eso en la totalidad del territorio se podía escuchar alguna emisora. En la actualidad la radio se reinventa para seguir vigente en la vida de los colombianos y no quedarse rezagado frente a los otros medios. La radio ha acompañado a los colombianos en los buenos y malos acontecimientos del país desde el comienzo del siglo XX. Las primeras ondas de radio en Colombia se propagaron a comienzos de 1920. Algunas familias adineradas introdujeron en el año 1923 los primeros receptores y transmisores de baja potencia. Pero fue hasta 1929 cuando el presidente Miguel Abadía Méndez, luego de varias solicitudes y demoras de equipos necesarios, inauguró la primera radiodifusora del país, la $\mathrm{HJN}$, más tarde la Radiodifusora Nacional". (revista semana)

Entre los años 1930 y 1940 surgió la llamada "edad de oro" de la radio colombiana, donde se fortaleció no solo la radio a nivel técnico incorporando equipos de última tecnología, sino que adicionalmente la construcción de público a través de los contenidos cada vez fue más fuerte. Dicho estatus que obtuvo este medio de comunicación, se mantuvo igual hasta mediados de los años noventa.

Sin embargo, con el advenimiento tecnológico y la reducción de la brecha digital, se ha generado una revolución de medios en nuestro país, permitiendo que nuevas 
miradas tengan voz dentro del espectro, y permitiendo así que medios alternativos tanto auditivos como audiovisuales e incluso multimediales, tengan mayor presencia, Algunas de las emisoras colombianas pasaron a la radio Online, una de ellas fue la emisora 'La Voz de Pereira' como una emisora básica, que en los años 30 cuando llegó la radio a la ciudad fue una radio análoga, hasta transformarse en lo que hoy conocemos como la radio Online, adaptada a las necesidades de la audiencia. Por esto ha sido una de las emisoras con mayor importancia en la ciudad, que luego de su desaparición renace cuando el creador del Digital Book en Colombia decide montar su propia emisora streaming con el nombre de 'La Voz de Pereira'.

Digitalización de la radio. "Hoy, los radiodifusores enfrentan una revolución similar a la experimentada, hace quince años, por la prensa escrita: cambio de la linotipia a la impresión computarizada. La tendencia actual en radio es la conversión de la técnica analógica a la digital y, por ende, a métodos de trabajo orientados al futuro. Lo que muchas estaciones están fríamente calculando, o incluso poniendo en práctica, es subirse al tren digital, el que puede muy rápido convertirse en parte de una red mundial de tráfico digital" (Mantilla, 1997).

Al aire WEB - Radio en internet: la innovación de la tecnología en comunicación trae la posibilidad de expansión para que los productores radiales y los comunicadores crezcan cada día. El Internet permite despejar el presente y proyectar un futuro prometedor para el medio radial. La radio en FM y AM ya no tienen la posibilidad de otorgar más frecuencias, pues el espectro electromagnético se encuentra completamente saturado. Es por esto que los productores radiales y los comunicadores se han visto en la obligación de buscar métodos alternativos para hacer radio. En diferentes países del mundo la radio por internet es una posibilidad realmente interesante, pero..., ¿cuándo lo será en Colombia? Implementar un medio comunicacional, como es la radio digital, posibilita crear un espacio de comunicación en internet, donde se generan incidentes comunicativos innovadores, mayor cobertura, puesto que el internet de banda ancha es más asequible y genera mayor número de usuarios a los cuales llegar con el uso de nuevos formatos radiales, por la interactividad, la ampliación de las audiencias y la facilidad de montaje donde no se requiere contemplar la limitación de espectro y los equipos necesarios son más económicos. Desde lo académico se convierte en una forma de estimular el desarrollo de la enseñanza y la profesión, contribuyendo con esto al progreso del País.

Al ser un canal de interactividad muy flexible y totalmente autónomo, le aporta a la descentralización del conocimiento. Permite a los usuarios utilizar la creatividad y la afinidad, creando contenido propio y fomentando la libertad de expresión.

Streaming emisora la Voz de Pereira. "La emisora la voz de Pereira, en el momento tiene una página la cual es automática y reproduce música género balada; sin embargo esta emisora será totalmente streaming, se están preparando equipos para acondicionar el lugar y un grupo de personas para que se ocupe de cada una de las secciones de esta nueva radio, se tendrá secciones de deportes, música variada, 
noticias y un locutor el cual estará encargado de toda la comunicación con los oyentes en la página que se tiene y página en redes sociales" (Marín, 2019).

\section{METODOLOGÍA}

Investigación cualitativa, tipo documental. Según María Eumelia Galeano (2016) “...El enfoque cualitativo aborda realidades subjetivas e intersubjetivas, que busca comprender desde la interioridad y las lógicas de pensamiento que guían a los actores sociales. Estudia la dimensión interna y subjetiva de la realidad social como fuente de conocimiento. La investigación social cualitativa apunta a la comprensión de la realidad como resultado de un proceso histórico de construcción a partir de las lógicas de sus protagonistas..."

Se aplicará como instrumento metodológico la revisión bibliográfica y entrevistas, las cuales nos ayudarán a facilitar gran parte de la obtención de datos de manera veraz y honesta, por medio de personas, documentos y material de archivo.

\section{RESULTADOS E IMPACTOS}

El impacto de esta investigación en la sociedad pereirana se dará por la necesidad que existe de que los jóvenes reconozcan la importancia de la radio como medio de comunicación, y sea evidente el paso de este medio análogo al medio digital. Desde la emisora 'La Voz de Pereira', las nuevas generaciones podrán conocer la llegada de esta emisora a Pereira, su desarrollo en la ciudad y cómo fue el proceso de migrar al streaming para sobrevivir a la era digital. 
1. Cebrián, M. (2008). La radio en Internet: de la ciberradio a las redes sociales y la radio móvil. Buenos Aires: La Crujía.

2. Cebrián, M. (2009). Expansión de la ciberradio. Enl@ ce Revista Venezolana de Información, tecnología y conocimiento. Recuperado de http://www. redalyc.org/html/823/82311100002/

3. Merayo, A. Formación, nuevos contenidos y creatividad sonora: apuestas para un tiempo de incertidumbre tecnológica. Martínez Costa, P. Et al. Reinventar la radio. Eunate. Pamplona.

Webgrafia:

Colombia, un país de radio. Tomado de Revista Semana:

https://www.semana.com/tecnologia/articulo/colombia-un-pais-de-radio/516027.

Febrero 2 de 2017 


\section{\begin{tabular}{l|l} 
PREPNDINP & MEEMRO DE LARE \\
ILUMNO
\end{tabular}}

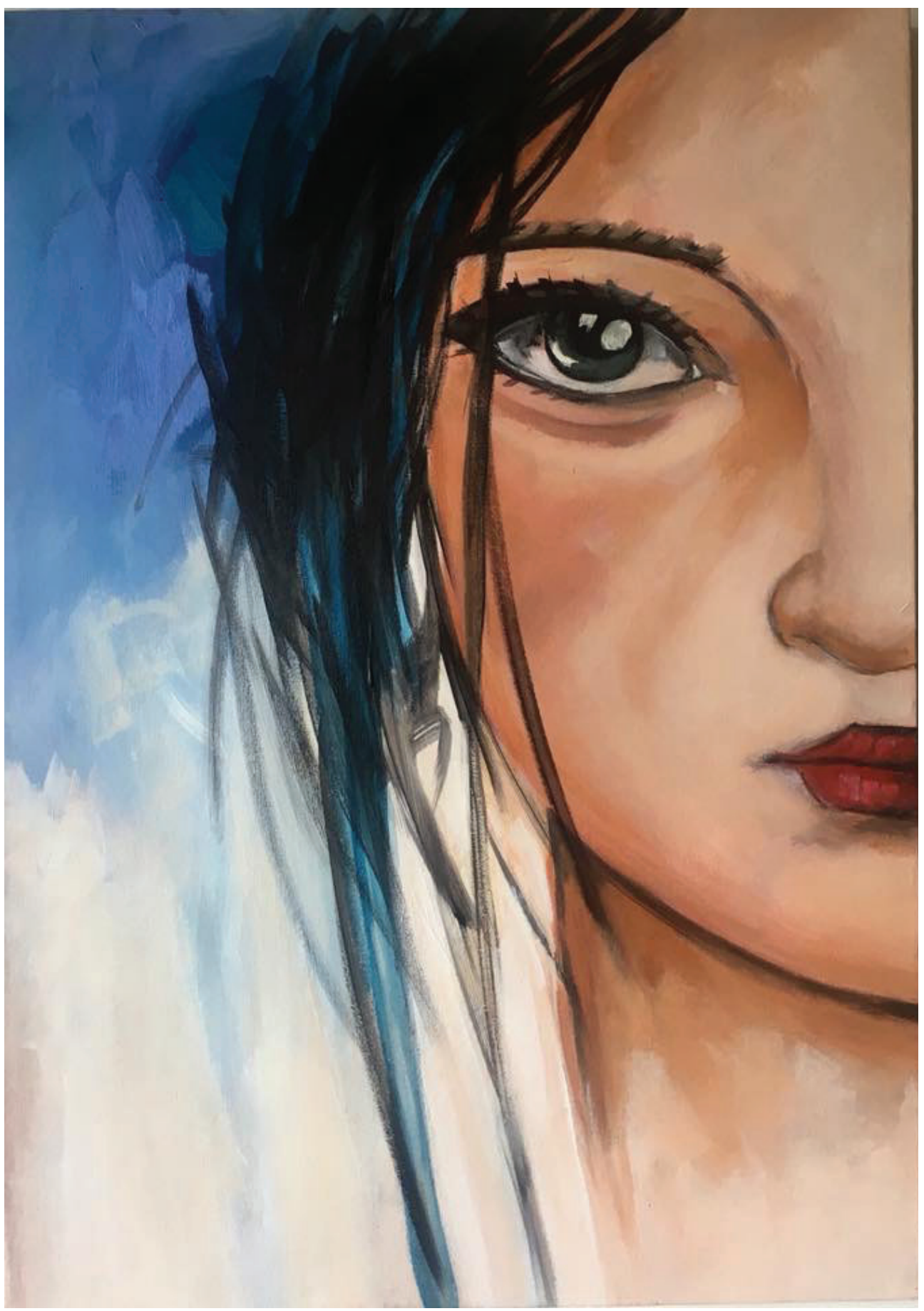

Acrílico sobre lienzo. De la serie "Rostros con rastros", Virginia Aristizábal Parra. 